\title{
Impact of Economic Growth on Social Security in Vietnam
}

\author{
Dr. Nguyen Minh Tri \\ Ho Chi Minh City University of Technology (HUTECH), Vietnam \\ Dr. Nguyen Anh Quoc \\ University of Social Sciences and Humanities \\ Viet Nam National University Ho Chi Minh City \\ Nguyen Mai Lam \\ Ph.D. Candidate \\ University of Social Sciences and Humanities \\ Viet Nam National University Ho Chi Minh City
}

\begin{abstract}
The impact of economic growth on social security in Vietnam is one of the basic factors that reflect the level and quality of the country's sustainable development. In recent years, Vietnam has achieved important achievements in economic growth, thereby creating material conditions to solve social security issues for all people. However, the benefits brought about by economic growth are not high, the quality of labor tends to decrease compared to the requirements; rich-poor gap tends to increase; social security implementation resources are mainly based on the budget; coverage and low level of support, has not been adjusted in time... Therefore, continuing research to provide more scientific bases for the policy decisions in order to find the necessary solutions to effectively guide economic growth to sustainable social security, it is urgent work today.
\end{abstract}

Keywords: Social security; Economic growth; Vietnam.

\section{Introduction}

A developed society has to be harmonic not only ensures human rights, but also enhances people's ability to prevent and overcome risks to make sure that all people have right to access and social security. Near 35 years (from 1986 to the present) of renovation and international integration, Vietnam has escaped from the group of poor and backward countries and entered the threshold of a middle-income country, people's lives have improved markedly. However, due to macroeconomic challenges, the economic growth rate did not meet the set plan, thus reducing investment resources for social security leading to the gap between rich and poor, inequality in the income, the rate of social insurance coverage is still low,... has been negatively affecting the socio-economic development goals in Vietnam today. This article analyzes the current situation and solutions to enhance the impact of economic growth on social security in Vietnam in the coming time.

\section{The impact of economic growth on social security in Vietnam}

Firstly, economic growth impacts employment creation. Employment creation is an important part of the socioeconomic development strategy, contributing to creating livelihoods for workers for a harmonious and sustainable development society. With a stable economic growth rate, together with the Party's leadership and the Government's administration through programs that effectively integrate with socio-economic development programs, implement projects in terms of employment credit at preferential interest rates from the National Fund for Employment (the National Fund for Employment is the nation's national reserve fund to create jobs and support employment services. National fundis created from the following sources: the state budget; assistance from domestic and foreign organizations and individuals to support jobs) has contributed to promoting economic restructuring, labor structure, linking vocational training with job creation, thereby increasing employment opportunities and improving labor relations. Looking back over the past years, job creation and labor market development have obtained positive results: in the period of 2010 - 2015, jobs have been created, creating jobs for about 7.8 million, of which, about 469 thousand people were sent to work abroad (Vietnamese Communist Party, 2016) and in 2019, the country created jobs for over 1.2 million workers, reaching $75.5 \%$ of the annual plan, equal to $99,5 \%$ in the same period of 2018 . Along with that, vocational training is concerned, step by step developing, contributing to the proportion of trained workers from less than 10\% (in 1990) to 58.6\% (in 2018) and reaching nearly 60\% (first 6 months of 2019). Employment sessions, the labor market information system gradually link employees and employers. 
The high growth rate in recent years, coupled with effective employment policies, have significantly affected the average income of workers. From 2007 and earlier, Vietnam was a low-income country with an average per capita income of less than 1,000 USD/person/year. By 2008, Vietnam became a low middle-income country, with an averageper capita income of 1,154 USD/person/year and increased to 2,590 USD/person/year in 2018 (General Statistics Office, 2019). Increasing income of the people over the years has contributed to improving the expenditure on life per capita at the current monthly price increased from 705 thousand VND (2008) to 3,876 thousand VND (2018)(General Statistics Office, 2019). Thus, with a high growth rate, stable jobs and increased income, living expenses in households are increasingly improved, the next year is higher than the previous year, contributing to improving the quality of life.

Although the unemployment rate has decreased from 2.28\% (in 2010) to 2.19\% (in 2018) (General Statistics Office, 2019), rural unemployment due to lack of qualifications and loss of land due to the urbanization process, as well as the "disguised unemployment" in urban areas still exist and tends to increase, causing significant consequences in the process of social security implementation. Moreover, our country's labor force now carries small production habits, practices, lack of dynamism and creativity, a sense of discipline, poor industrial manners; limited teamwork knowledge and skills, reluctant to promote initiative and share work experience. Therefore, the risk of losing competitiveness in the market is very large when participating in the international labor division process.

Secondly, economic growth impacts poverty reduction. Economic growth to eliminate hunger and reduce poverty is a major policy of the Party and State of Vietnam in order to ensure people their material and spiritual needs. If economic growth is not associated with poverty reduction, it will make the society develop "crippled" and increase the intrinsic conflict of the country more and more complicated; on the contrary, economic growth associated with poverty reduction will create opportunities for disadvantaged people to escape poverty, and have opportunities for income and consumption opportunities as social entities. Therefore, in the process of socio-economic development, our Party and State pay great attention to people, especially the poor, and are considered as one of the typical countries in the international public opinion that present the millennium goals on hunger eradication and poverty reduction. According to national standards, the percentage of poor households has decreased from 30\% in 1992 to 5.8\% in 2016; According to the multidimensional poverty line, the poverty rate has decreased from $14.2 \%$ (2010) to $6.8 \%$ (2018), particularly in poor districts, it has decreased by $4 \%$ (General Statistics Office, 2019). According to the Government's report on the results of implementing the 2017 socio-economic development plan; Socio-economic development plan in 2018, up to now, most of social policy beneficiaries, children under 6, the poor, ethnic minorities in disadvantaged areas have had health insurance. International; issuing health insurance cards for over 34.3 million people, supporting the purchase of health insurance cards for over 15.1 million people. The political determination in the struggle to reduce poverty of our Party and State has created conditions for all people to enjoy the fruits of economic growth, thereby rising out of poverty, improving their material and fine lives.

However, the impact of economic growth on poverty reduction still has limitations, such as unsustainable poverty reduction, the highest risk of falling back into poverty is in the ethnic minority and remote areas. The most remote area is ethnic minorities (some districts and communes account for up to 50\%) (Vietnamese Communist Party, 2016).. The greater the difference in living and cultural enjoyment between the urban and suburban people; The rich-poor gap tends to increase rapidly, however, according to the General Statistics Office (2019), Group 1 (20\% of the lowest-income people) is about 40,5 USD/month, Group 5 ( $20 \%$ of people) has the highest income) is $405 \mathrm{USD} / \mathrm{month}$. The income gap coefficient between group 1 and group 5 tends to widen by 10 times (In 1995 it was 6.99 times, in 2006 it was 8.4 times, in 2013 it was 9.55 times) (General Statistics Office, 2019). This shows that the average income in Vietnam between the richest and the poorest groups has not improved, but tends to increase due to unequal sharing of opportunities and achievements of economic growth, which is beneficial for the group who already have a better life. These limitations have been identified by our Party: "The risk of falling back into poverty is still high; rich-poor gap between regions and population groups is large. The percentage of poor and near-poor households in remote areas, especially among ethnic minorities is still high (up to 50\% in some districts and communes). A number of policies on social security and poverty reduction are overlapping, inconsistent, not effective and not encouraging the poor to rise out of poverty" (Vietnamese Communist Party, 2016).

Thirdly, economic growth affects the legal system of social insurance. In the process of development and integration, Vietnam implementing social insurance is one of the key tasks of the socio-economic development process, ensuring the rights and obligations of millions of workers. dynamic. With the high economic growth rate, it has contributed to the expansion of social insurance participants. The social insurance system is completed with increasingly abundant content and forms, in order to share and provide practical assistance to people participating in social insurance. Subjects participating in social insurance increased steadily every year, as of October 31, 2019, the total number of people participating in compulsory social insurance was 14,915 million, reaching $97.5 \%$ of the plan. 
Increasing 146 thousand people compared to September 2019; an increase of 462 thousand people compared to December 2018. As of December 31, 2018, the total number of people receiving monthly social insurance benefits was 1.2 million, a decrease of 1.3\% compared to 2017, estimated at 46,129 billion VND(General Statistics Office, 2019)... The number of beneficiaries of unemployment benefits, support of vocational training increased, employment was increased sharply. Currently, all 63 provinces and cities pay monthly pensions and social insurance benefits through the postal system.

However, the impact of economic growth on social insurance still faces challenges with the rate of participation in social insurance accounts for less than 1/3 of the labor force; The rate of participation in unemployment insurance is also quite low. Laborers in the formal sector have social insurance. The coverage of social insurance is low, though it has improved in recent years. According to statistics of Vietnam Social Insurance, in 2011 there were 10.2 million people participating in social insurance, in 2017 there were 13.8 million people participating in, in 2019 there were 14.5 million people participating. However, the rate of social insurance coverage is only about a quarter of the labor force aged 15 and over, according to GSO, although the coverage has increased from $20.3 \%$ in 2011 to $41.1 \%$ in 2018 (General Statistics Office, 2019). This means that a large part of the labor force has not yet participated in social insurance and will not benefit from current and future social insurance after reaching retirement age. Moreover, the number of people participating in voluntary social insurance accounts for only a very small percentage of the total number of employees participating in social insurance. After 10 years of implementing the voluntary social insurance policy, only about 300,000 people participated. Meanwhile, the informal sector now has about 40 million employees. This shows that the employees are not aware of the benefits of participating in voluntary social insurance, voluntary social insurance is not attractive enough or the employees can't afford to pay social insurance voluntarily.

Fourthly, economic growth affects incentives for people with meritorious services. From 1945 up to now, the Communist Party of Vietnam has always grasped the following point of view: "Implementing the policy of social incentives and mobilizing the entire population to participate in returning the favours and being grateful to benefactor of the elderly, revolutionary veteran, people with meritorious services to the country, Vietnamese Heroic Mothers, wounded soldiers and parents, wives and children of martyrs, who are entitled to social policies " (Communist Party of Vietnam, 2001). This is a consistent policy in the Party's documents and is adjusted according to the country's socioeconomic situation so that the beneficiaries of the policy have a stable life.

Thoroughly grasping the above point of view, in the course of revolution, the Party has advocated preferential treatment for people with meritorious services to the revolution and supported people in especially difficult circumstances, the poor and ethnic minorities, ensuring $98.5 \%$ of households with living standards equal to or higher than the average living standards of residents in the same area(Nguyen Trong Đam, 2016) The search, collection of martyrs remains and identification of martyrs' remains missing are continued. The movement of "Return the favour" has been actively responded to by the Vietnam Fatherland Front, ministries, branches and mass organizations from the central to local levels, organizations and social communities, becoming the traditional beauty of the nation with activities, such as donation of gratitude savings book; building and repairing gratitude houses; building the Fund of "Return the favour"; giving gratitude garden, warm coats for mothers, silk clothes for grandmothers; take care of Heroic Vietnamese Mothers, look after relatives of martyrs, sponsor children of war invalids and martyrs' children, contribute to socio-political stability, also strengthen people's confidence in the Party's leadership, Government. However, the implementation of the Ordinance on preferential treatment for people with meritorious services still has a number of subjects that have not been reviewed and verified because the documents and papers are no longer available and lack of evidence. Personnel is in charge of identifying subjects in units and localities frequently change. The coordination between upper and lower levels in some localities in the inspection direction is not good, the appraisal of dossiers is simple, inconsistent and the social incentive policies are often slow and incompatible with economic policies Fifthly, economic growth affects the protection and care of the people. Protection and care for the people 's health is a mean to ensure that all people have good health and physical strength to participate in production activities, contributing to the implementation of economic growth targets and ensuring Sustainable social security for the present and the future. Therefore, our Party and State always thoroughly understand that investment in health is investment in people, economic growth goes hand in hand with comprehensive improvement of people's lives towards sustainable development. As of December 2018, the whole country had 49,984 medical examination and treatment facilities, organized the medical apparatus completed from grassroots to provinces and cities in the direction of universal, intensive and modern, quality of staff Ministry of health is raised. Public health indicators have been raised, such as the death rate of children under 5 has decreased by 81\%o (1990) to about 21. \%o (2017); The percentage of malnourished children has decreased from $50 \%$ to about $13.4 \%$, respectively; the percentage of children under one year old fully vaccinated accounted for $96.4 \%$; Their average age is 73.5 years old today, compared to regional healthcare, it is clearly a great achievement of health policy (Thailand's average life expectancy is 72 years; Malaysia has an average 
life expectancy of 73.3 years). Currently, the rate of participation in health insurance covers $83 \%$ of the population (equivalent to 75915.2 thousand people). This has created better health care for people of all strata of society, promoting social progress.

In addition, the impact of economic growth on the protection and care of the people's health is limited: Although the health network has been expanded, its distribution is not reasonable and not convenient for people. Quality of medical examination and treatment has not met requirements, especially at grassroots levels. Overcoming the hospital overload is still slow (Vietnamese Communist Party, 2016). Medical ethics of a part of health workers is not good. Overcoming the hospital overload is still slow, especially at the last level. Preventive medicine is still present. The implementation of the market price roadmap for health services and autonomy mechanism in public health units is still slow. Mechanisms and policies on health insurance, hospital fee collection and medical examination and treatment for the poor, people in remote, isolated areas and ethnic minority areas are still inadequate. Investments and enjoyment of health and other services are increasingly inclined towards people with more money living in urban areas.

\section{Solutions to improve the impact of economic growth on social security in Vietnam}

Firstly, maintaining a stable macroeconomic environment, on the basis of which promote restructuring the economy associated with renewing the economic growth model, improving productivity, quality and operational efficiency of economy for people. In order to promote rapid and sustainable economic growth for the purposes of social security and welfare, creating important conditions for social progress, it's necessary to consider the four economic factors that need "stimulating"strongly: that there is a positive policy towards promoting the private economy to become the No. 1 driving force of economic growth; Perfecting the market economy mechanism operating in a transparent public administration, aiming at the State to realize the role of development development; Domestic and international factors must be seen as co-drivers of economic growth; And there is a policy to mobilize sufficient human resources for economic growth in the direction of equal opportunity for every capable and demanded employee to have a job. On that basis, Vietnam promotes economic restructuring towards service-industry-agriculture, focusing on developing valueadded industries and modern scientific content, creating resources to implement social security for all people.

Secondly, implement harmonious growth policies. At the request of a harmonious growth model, policies should be improved in two directions: Making all strata of the population (rich and poor) in society (dynamic or underdeveloped areas) participate in economic growth to benefit directly from the growth results;To promptly implement the redistribution of the growth results among different population strata, regions and regions throughout the country in order to create a positive and equitable move on social progress for people.

Following this orientation, a number of policies need to be paid attention to creating equality of opportunity to participate in the process of economic growth for everyone: Strongly develop the connected infrastructure system, especially the transportation system and information system between key areas to attract investment and remote areas which provide labor sources, eliminate isolation for the underdeveloped areas at present; To harmonize the redistribution through rational regulation of income among population strata with the building and consolidation of a multi-tiered social security system. In the specific circumstances of our country today, the objects of social security are very diverse, so it is necessary to build, strengthen and increasingly consolidate the multi-level social security policy system; Strengthen the provision of educational, health and social services in remote areas so that they are eligible for knowledge or skills to directly participate in income generation.

Thirdly, improve the policy of distributing the fruits of economic growth growth to human-related fields. Using the economic growth results to improve the aspects related to human and social development: the process of economic growth must be controlled regularly and strictly by the commune development targets. In which, the focus is on hunger eradication, poverty reduction, social justice, job creation, and indicators related to the comprehensive development of human beings, such as education, (public) health, education, and sports, culture - art. At the same time, the economic growth policies associated with creating conditions are increasingly fair for everyone about development opportunities. This involves: Implementing policies that enable everyone to be equipped with capacities to participate in the implementation of economic growth; Implement policies to make full use of and ensure everyone has the opportunity to participate in economic processes to create growth.

With that, the fruits of economic growth are always associated with improving the standard of living for the people, through the policy of income distribution and redistribution. The human-growth model dictates the effective use of two methods of income distribution: (i) Functional income distribution, that is, each person's income is determined on the basis of the contribution of the number and quality of resources they contribute to generating income for the economy; (ii) Income redistribution, in the form of direct (tax, subsidy) and indirect (through price policy access to public services) to contribute to the regulation of income among different strata of society. 
Fourthly, promote the formulation, adjustment and perfection of mechanisms and policies for social security. It's necessary to identify the social issues that need to focus on solving first, meeting the urgent objectives of society. In our opinion, we need to focus on specific solutions:

- Regarding policies to well solve jobs and incomes of all strata of the population. This is considered the most sustainable way to make social progress in our country. The Resolution of the 12th Congress of the Party affirmed: "Creating opportunities for people to have jobs and improve incomes. Ensuring equitable wages, income, living conditions and reproduction of labor power" (Vietnamese Communist Party, 2016), so it is necessary to have mechanisms and policies to further promote the role of the economic sector. Private sector in the development process by continuing to create a healthy and equal business environment between the private sector and the state economic sector in accordance with the principles of the market economy. Support the private sector with practical policies, close to practical needs. To attach importance to raising the quality of human resources; Vocational training and job creation for laborers must be associated with socio-economic planning, economic development programs, trades and orientations for economic restructuring of each locality. Mobilizing all investment resources to participate in vocational training. Along with that, perfecting and implementing labor protection policies, promoting labor export is an important solution in creating jobs, meeting practical needs, contributing to increasing incomes and improving qualifications. skills for current workers.

- Regarding policies on poverty reduction. The Party and the State should drastically incorporate the multi-dimensional poverty reduction goals into the national socio-economic development strategy. Directing provinces and cities to formulate detailed plans of poverty reduction programs and policies according to specific roadmaps with practical solutions, close to the assistance needs of the poor with specific conditions of the provinces and cities, avoid burning phase; checking and classifying poor and near-poor households objectively and accurately to take appropriate support measures.

- Regarding policies to develop the social insurance system, increase the coverage of social insurance, health insurance and unemployment insurance as the main pillars of the social security system. Currently, except for health insurance, coverage of social insurance and unemployment insurance is low and mostly new in the formal economic sector. The informal economic sector with the large number of labors in our country has largely not yet participated in social insurance. This not only makes social insurance not promote the superiority in ensuring social security, while creating a great social burden when these people reach the working age; but also putting the social insurance fund at risk of unsustainability.

- Regarding health policy: Promote medical socialization, pilot establishment of medical examination and treatment facilities in the form of public-private partnership and hospital management model such as public enterprises; accelerate the implementation of universal health insurance. Encourage and support creative ideas, promote innovation and development, especially in the fields of economy, society, science - technology, culture, art ... Social Development Management focus on building a reasonable social development model, focusing on low-income social strata on the basis of constantly improving people's lives.

Fifthly,strengthening social management on the basis of democracy, rule of law, and at the same time enlisting international support through strengthening propaganda and promoting foreign aid-seeking programs; use for the committed purpose upon receiving aid; publicity and transparency in the use of international aid.

\section{Conclusion:}

The impact of economic growth on social security in Vietnam has contributed to improving the people's living standards clearly, ensuring equity and social progress, the unemployment rate has decreased over the years and the distance between the richest groups and the poorest group are shortened. The coverage of social insurance is expanded, the health care and development contributes to improving the production capacity to participate in the labor market, promoting economic growth, thereby creating human development in the economy in Vietnam. This is an important driving force to ensure that Vietnam will soon achieve the goal of wealthy people, strong country, justice and civilized society. But challenges remain in the process of socio-economic development. Therefore, the orientation is necessary to direct the fruits of economic growth to social welfare in a proper and effective manner, in order to realize the objective wealthy people, strong country, justice and civilized society. 


\section{References}

Communist Party of Vietnam. (2001).Document of the Ninth National Congress. National Political Publishing House, Hanoi, p.106.

Vietnamese Communist Party. (2016).Document of the 12th National Delegation. Central Office of the Communist Party, Hanoi, p.238, p.256, p. 259, p.157, p.136

General Statistics Office. (2019).Vietnam Statistical Yearbook 2018. Statistical Publishing House, Hanoi,p.183, p.833, p.150, p.854, p.834, p.203, p.203

Nguyen Trong Đam. (2016). Promote social security policies to ensure progress and social justice in our country today. Retrieved February 19, 2018 from http://tapchikhxh.vass.gov.vn/day-manh-chinh-sach-an-sinh-xa-hoibao-dam-tien-bo-va-cong-bang-xa-hoi-o-nuoc-ta-hien-nay-n50093.html 